OPEN ACCESS

Edited by:

Marc Ribo,

Vall d'Hebron University

Hospital, Spain

Reviewed by:

Fabien Chauveau, INSERM U1028 Centre de Recherche

en Neurosciences de Lyon, France Marta Rubiera

Vall d'Hebron University Hospital, Spain

${ }^{*}$ Correspondence:

Wengui Yu

wyu@uci.edu

Specialty section:

This article was submitted to

Stroke,

a section of the journal

Frontiers in Neurology

Received: 04 October 2018 Accepted: 25 April 2019 Published: 24 May 2019

Citation:

Yu W and Jiang W-J (2019) A Simple Imaging Guide for Endovascular

Thrombectomy in Acute Ischemic

Stroke: From Time Window to

Perfusion Mismatch and Beyond.

Front. Neurol. 10:502

doi: 10.3389/fneur.2019.00502

\section{A Simple Imaging Guide for Endovascular Thrombectomy in Acute Ischemic Stroke: From Time Window to Perfusion Mismatch and Beyond}

\author{
Wengui $\mathrm{Yu}^{1 *}$ and Wei-Jian Jiang ${ }^{2}$ \\ ${ }^{1}$ Department of Neurology, University of California Irvine, Irvine, CA, United States, ${ }^{2}$ New Era Stroke Care and Research \\ Institute, The Rocket Force General Hospital, Beijing, China
}

Keywords: acute ischemic stroke (AIS), clinical-imaging mismatch, endovascular thrombectomy (EVT), ischemic penumbra, perfusion mismatch, symptomatic intracranial hemorrhage (sICH)

\section{INTRODUCTION}

Recent advances in medical and endovascular therapy have revolutionized stroke care. Intravenous thrombolysis (IVT) with tissue plasminogen activator (tPA) was shown to be effective for acute ischemic stroke (AIS) within $3 \mathrm{~h}$ of symptom onset in 1995 (1). Subsequent studies extended the time window to $4.5 \mathrm{~h}(2,3)$. However, IV tPA was not very effective for stroke from large vessel occlusion (LVO) $(4,5)$.

Endovascular thrombectomy (EVT) was originally reported for patients with AIS from LVO in early 2000s (6-8). In 2013, 3 prospective, multi-center randomized controlled trials (RCTs), including the Interventional Management of Stroke (IMS) III (9), Mechanical Retrieval and Recanalization of Stroke Clots Using Embolectomy (MR RESCUE) (10), and Intra-Arterial vs. Systemic Thrombolysis for Acute Ischemic Stroke (SYNTHESIS EXP) (11), failed to show significant clinical benefit of EVT over standard medical therapy. No mandatory requirement for vascular imaging to screen for $\operatorname{LVO}(9,11)$, nascent devices (9-11), and slow enrollment (10) may be the major limitations of these studies. However, a post hoc analysis of data from IMS III showed significant outcome benefit of EVT in the subgroup of patients with proven LVO (12).

In 2015, 5 RCTs independently demonstrated the safety and efficacy of EVT for AIS from LVO in the anterior circulation within 6-12 h of symptom onset (13-17). Three additional studies reported similar findings in 2016 (18-20). In early 2018, DWI or CTP Assessment with Clinical Mismatch in the Triage of Wake-Up and Late Presenting Strokes Undergoing Neurointervention (DAWN) and Endovascular Therapy Following Imaging Evaluation for Ischemic Stroke (DEFUSE 3) trials extended the time window to $16-24 \mathrm{~h}$ after last known well $(21,22)$. These studies also showed that thrombectomy during the extended time window was not associated with significant higher risk of symptomatic intracranial hemorrhage $(\mathrm{sICH})(21,22)$.

In this review, we seek to appraise various imaging modalities used in the landmark studies and to propose a simple and efficient imaging guide for EVT in the real-world practice.

\section{Imaging Modalities Used in Landmark RCTs}

There were great variabilities in the use of imaging tools for patient selection in the recent RCTs. The key inclusion/exclusion criteria, main imaging modalities, and the thrombectomy devices used in the landmark studies are summarized in Table 1. Non-contrast CT and CTA were used to select patients with severe deficit and low infarct volume from LVO in most of the clinical trials 
(13, 15-20, 22). Advanced imaging tools, including CT perfusion (CTP), diffusion/perfusion MRI, and MRA, were used to identify patients with perfusion mismatch (i.e., small infarct and large ischemic penumbra) in EXTEND-IA, SWIFT PRIME, DEFUSE 3, and EXTEND-IA TNK trials (14, 17, 22, 23), or clinicalimaging mismatch (i.e., severe deficit and small infarct volume) in the DAWN trial (21). In ESCAPE trial, multiphase CTA was used to evaluate the extent of collateral circulation and patients with no or minimal collaterals were excluded from the study (15).

\section{CT and Alberta Stroke Program Early CT Score (ASPECTS)}

Non-contrast CT is widely available and can be performed within a few minutes of arrival. It is very sensitive in detecting hemorrhage $(24,25)$. During the first few hours of AIS, noncontrast CT is usually normal. A visible hypoattenuation on the CT is often irreversible (25). ASPECTS was developed to quantify early ischemic changes on non-contrast CT $(26,27)$. The scoring system divides the MCA territory into 10 zones on 2 axial CT slices at the levels of basal ganglion and the superior ganglionic margin (26). One point is subtracted for early ischemic change in each zone. A normal CT scan without any sign of ischemic change gets 10 points as shown in Figure 1. A score of 0 indicates diffuse ischemic changes in the entire MCA territory $(26,27)$.

ASPECTS can also be derived from CT angiographic (CTA) source image $(28)$ or DWI image $(16,17,29)$. CTA source imageand DWI-ASPECTS are more sensitive than non-contrast CT in the detection of early ischemic changes and prediction of final infarct volume $(28,29)$. The limitation of MRI is that it cannot be performed timely for acute stroke therapy at some medical centers.

Of note, ASPECTS score has a few limitations. First, it is limited to the anterior circulation (26). Second, it is based on anatomical structure with an unequal weighing of brain regions $(30,31)$. Its correlation with lesion volume is dependent on lesion location $(31,32)$. Last, it has poor sensitivity and inter-rater

\footnotetext{
Abbreviations: AIS, acute ischemic stroke; ASPECTS, Alberta Stroke Program Early CT Score; CT, computed tomography; EVT, endovascular thrombectomy; IQR, interquartile range; IVT, intravenous thrombolysis; OTT; onset to treatment time; RCTs, randomized controlled trials; sICH, symptomatic intracranial hemorrhage; tPA, tissue plasminogen activator; DAWN, Diffusion Weighted Imaging (DWI) or Computerized Tomography Perfusion (CTP) Assessment with Clinical Mismatch in the Triage of Wake Up and Late Presenting Strokes Undergoing Neurointervention; DEFUSE 3, Endovascular Therapy Following Imaging Evaluation for Ischemic Stroke; ESCAPE, Endovascular Treatment for Small Core and Anterior Circulation Proximal Occlusion with Emphasis on Minimizing CT to Recanalization Times; EXTEND-IA, Extending the Time for Thrombolysis in Emergency Neurological Deficits-Intra-Arterial trial; IMS III, Interventional Management of Stroke III trial; MR CLEAN, Multicenter Randomized Clinical Trial of Endovascular Treatment for Acute Ischemic Stroke in the Netherlands; MR RESCUE, Mechanical Retrieval and Recanalization of Stroke Clots Using Embolectomy; REVASCAT, Randomized Trial of Revascularization with Solitaire FR Device vs.Best Medical Therapy in the Treatment of Acute Stroke Due to Anterior Circulation Large Vessel Occlusion Presenting Within $8 \mathrm{~h}$ of Symptom Onset; SWIFT PRIME, Solitaire with the Intention for Thrombectomy as Primary Endovascular Treatment trial; SYNTHESIS EXP, Intra-Arterial vs. Systemic Thrombolysis for Acute Ischemic Stroke (SYNTHESIS EXP) trial; THERAPY, The Randomized, Concurrent Controlled Trial to Assess the Penumbra System's Safety and Effectiveness in the Treatment of Acute Stroke.
}

reliability for early ischemic changes $(32,33)$. However, the lower inter-rater reliability can be overcome by training (34).

ASPECTS score was found to be a strong predictor of clinical outcome after EVT $(13,16,35)$. There was no difference in outcome between patients with ASPECTS 6-7 and 8-10 (16). A meta-analysis of the pooled data from the 5 landmark studies published in 2015 showed a clear benefit of thrombectomy in patients with ASPECT $\geq 6$ (35). When the treatment effect was analyzed for the 3 ASPECTS strata of $0-5,6-8$, and 9-10, there was a strong and consistent treatment effect for both ASPECTS 6-8 and 9-10 group with an adjusted odds ratio of 2.34 (95\% CI: $1.68-3.26)$ and 2.66 (95\% CI: 1.61-4.40), respectively (35). There was no clear benefit for the 121 patients with ASPECT $0-5$. These findings appear to have validated the use of ASPECTS score 6-10 as surrogate marker of small infarct volume.

\section{CT Angiography (CTA) for Screening for LVO}

CTA of head and neck is a contrast study with high sensitivity and specificity for evaluation of cerebral vasculature and LVO (36). It also provides important information on collaterals, aortic arch, and cerebral ischemia (37-40). CTA may help interventionist to choose treatment strategy and reduce puncture-to-reperfusion time (39).

Decreased contrast enhancement on CTA source images is indicative of reduced cerebral blood volume (CBV) (34). CTA source images are more sensitive in predicting final infarct volume and outcome than non-contrast CT $(28,38,40)$. Of note, slow contrast injection and quick image acquisition can lead to an overestimation of the infarct size (41).

Most landmark studies used CTA to select patients with severe deficit from LVO for EVT (13-22).

\section{CTA for Assessment of Collateral Circulation}

Collateral circulations are highly variable among patients (38, 42). They directly affect the size of ischemic penumbra and infarct progression after LVO $(37,42-44)$. CTA is the most commonly used imaging modality to assess collaterals (42). Multiphase CTA is better than conventional CTA because of the ability to examine collateral flow with time resolution (38). Dynamic CTA is able to evaluate time to retrograde filling and visualize distal branches of the cerebral artery trees. Digital subtraction angiography remains the gold standard given its triphasic evaluation of arterial, capillary, and venous circulation with high temporal and spatial resolution $(38,39)$. The degree of leptomeningeal collaterals can be semi-quantified by comparing the retrograde pial arterial filling to the contralateral hemisphere $(37,43)$. A major limitation of collateral assessment on CTA is that it is a single snap shot in time of contrast and may misdiagnose adequate collaterals as poor if the image is acquired early in the arterial phase $(42,43)$.

Optimal collateral circulation is associated with slower infarct progression and may allow for EVT outside of the traditional time window $(43,45)$. A good leptomeningeal collateral flow is associated with better outcome, lower rates of sICH and mortality after EVT $(42,44,46,47)$. A large infarct core and poor 
TABLE 1 | Landmark studies of EVT for AIS from LVO in the anterior circulation.

\begin{tabular}{|c|c|c|c|c|c|}
\hline Study & Patient (n) & Key inclusion criteria & Key exclusion criteria & $\begin{array}{l}\text { Main imaging } \\
\text { modalities }\end{array}$ & EVT devices \\
\hline MR CLEAN (13) & 233 & $\begin{array}{l}\text { Age } \geq 18, \mathrm{NIHSS} \geq 2, \mathrm{LVO} \\
\mathrm{IVT}<4.5 \mathrm{~h}, \mathrm{EVT}<6 \mathrm{~h}\end{array}$ & $\begin{array}{l}\mathrm{BP}>185 / 110 \mathrm{mmHg} \text {, } \\
\text { coagulopathy, active or recent } \\
\text { hemorrhage }\end{array}$ & $\begin{array}{l}\text { CT, CTA, CT perfusion } \\
(68 \%)\end{array}$ & Retrievable stent \\
\hline EXTEND-IA (14) & 35 & $\begin{array}{l}\text { Age } \geq 18, \mathrm{NIHSS} \geq 6, \mathrm{LVO}, \\
\mathrm{IVT}<4.5 \mathrm{~h}, \text { ischemic core }< \\
70 \mathrm{~mL}, \text { mismatch volume } \geq \\
10 \mathrm{~mL}, \\
\mathrm{EVT}<6 \mathrm{~h}\end{array}$ & $\begin{array}{l}\text { Intracranial hemorrhage, any } \\
\text { terminal illness }\end{array}$ & CT, CTA, CT perfusion & Solitaire device \\
\hline ESCAPE (15) & 165 & $\begin{array}{l}\text { Age } \geq 18, \text { NIHSS } \geq 5, \text { LVO } \\
\text { IVT }<4.5 \mathrm{~h}, \text { small infarct core, } \\
\text { EVT }<12 \mathrm{~h}\end{array}$ & $\begin{array}{l}\text { ASPECTS } 0-5 \text {, } \\
\text { no or minimal collaterals }\end{array}$ & CT, CTA & $\begin{array}{l}\text { Available } \\
\text { thrombectomy } \\
\text { device }\end{array}$ \\
\hline SWIFT PRIME (16) & 98 & $\begin{array}{l}\text { Age } 18-80, \text { NIHSS } 8-29, \text { LVO, } \\
\text { IVT }<4.5 \mathrm{~h} \text {, small to moderate } \\
\text { infarct core, } \\
\text { EVT }<6 \mathrm{~h}\end{array}$ & $\begin{array}{l}\text { Hemorrhage, tumor or vacuities } \\
\text { on CT or MRI, } \\
>1 / 3 \mathrm{MCA} \text { territory or } 100 \mathrm{ml} \\
\text { infarct, DWI-ASPECTS } \leq 5\end{array}$ & CT, CTA, CT perfusion & $\begin{array}{l}\text { Solitaire stent } \\
\text { retriever }\end{array}$ \\
\hline REVASCAT (17) & 103 & $\begin{array}{l}\text { Age 18-80, NIHSS } \geq 6, \text { LVO, } \\
\text { IVT }<4.5 \mathrm{~h}, \mathrm{EVT}<8 \mathrm{~h}\end{array}$ & $\begin{array}{l}\text { Large ischemic core (ASPECTS } \\
\leq 7 \text { on CT or } 6 \text { on DWI MRI) }\end{array}$ & CT, CTA, MRI & $\begin{array}{l}\text { Solitaire stent } \\
\text { retriever }\end{array}$ \\
\hline THERAPY (18) & 108 & $\begin{array}{l}\text { Age } 18-85, \text { NIHSS } \geq 8, \mathrm{LVO}, \geq \\
8 \mathrm{~mm} \text { clot length }\end{array}$ & $\begin{array}{l}>1 / 3 \text { MCA territory infarct, } \\
\text { cervical ICA stenosis/occlusion }\end{array}$ & CT, CTA & Penumbra \\
\hline THRACE (19) & 414 & $\begin{array}{l}\text { Age 18-80, NIHSS 10-25, LVO, } \\
\text { IVT }<4 \mathrm{~h}, \mathrm{EVT}<5 \mathrm{~h}\end{array}$ & Cervical ICA stenosis/occlusion & CT, CTA, or MRA/MRI & $\begin{array}{l}\text { Stent retriever, } \\
\text { Penumbra }\end{array}$ \\
\hline PISTE (20) & 65 & $\begin{array}{l}\text { Age } \geq 18, \mathrm{NIHSS} \geq 6, \mathrm{LVO}, \mathrm{IVT} \\
<4.5 \mathrm{~h}, \mathrm{EVT}<6 \mathrm{~h}\end{array}$ & $\begin{array}{l}\text { Contraindicated for IVT, > 1/3 } \\
\text { MCA territory infarct, }\end{array}$ & CT, CTA & $\begin{array}{l}\text { Stent retriever, } \\
\text { Penumbra }\end{array}$ \\
\hline DAWN (21) & 107 & $\begin{array}{l}\text { Age } \geq 18, \text { NIHSS } \geq 10, \text { LVO, } \\
\text { small infarct core }(<1 / 3 \mathrm{MCA} \\
\text { territory), a mismatch between } \\
\text { clinical deficit and infarct volume } \\
\text { EVT 6-24 } \mathrm{h}\end{array}$ & $\begin{array}{l}\text { Rapid improvement in neuro } \\
\text { status, active or recent } \\
\text { hemorrhage, Coagulopathy }\end{array}$ & $\begin{array}{l}\text { CT, CTA, MRA, CT } \\
\text { perfusion, MR } \\
\text { perfusion/diffusion }\end{array}$ & $\begin{array}{l}\text { Trevo retriever, } \\
\text { Solitaire, or } \\
\text { Penumbra }\end{array}$ \\
\hline DEFUSE 3 (22) & 92 & $\begin{array}{l}\text { Age } 18-85, \mathrm{NIHSSS} \geq 6 \text {, LVO, } \\
\text { ischemic core }<70 \mathrm{ml} \text {, } \\
\text { mismatch ratio }>1.8 \text {, mismatch } \\
\text { volume } \geq 15 \mathrm{ml} \text {, or DWl volume } \\
<25 \mathrm{ml} \text { EVT } 6-16 \mathrm{~h}\end{array}$ & $\begin{array}{l}\mathrm{BP}>185 / 110 \mathrm{mmHg} \\
\text { coagulopathy, ASPECTS score } \\
<6 \text { on non-contrast CT }\end{array}$ & $\begin{array}{l}\text { CT perfusion } 75 \%, \text { MR } \\
\text { perfusion/diffusion 25\% }\end{array}$ & Trevo retriever \\
\hline
\end{tabular}

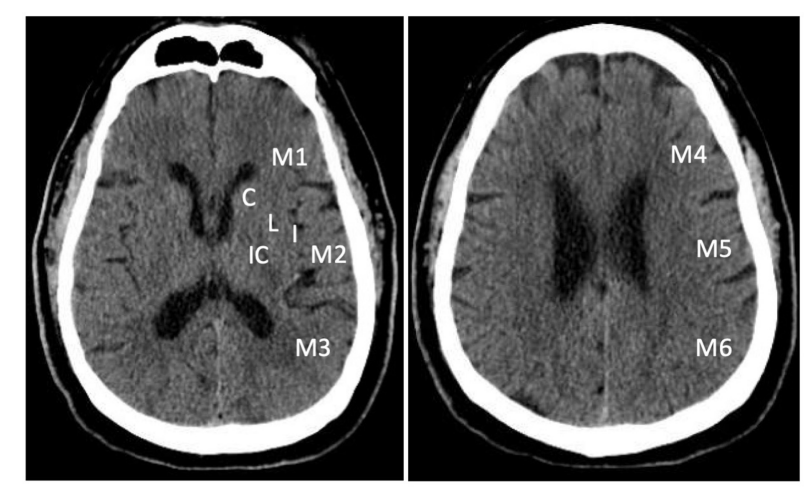

FIGURE 1 | Alberta Stroke Program Early Computed Tomography Score (ASPECTS). The scoring system divides the MCA territory into 10 zones at ganglionic and supra-ganglionic levels: 6 for cortical regions (M1-M6), and 4 subcortical regions ( $\mathrm{C}$, caudate; L, lentiform; IC, internal capsule; and I, insular ribbon).

collaterals were shown to be strong predictors of poor functional outcome $(46,47)$. Based on these findings, the ESCAPE trial excluded patients with minimal or no pial collaterals (15).
Collateral assessment on CTA matched with the ASPECTS score on non-contrast CT. Minimal or no pial collaterals in $>50 \%$ of MCA distribution was associated with an ASPECTS score of 5 or less (39). The DAWN and DEFUSE 3 trials demonstrated the benefit of late recanalization within 16-24 h using clinical-infarct mismatch profile indicative of good collaterals $(21,22)$.

Recent systemic review and meta-analysis have confirmed the favorable impact of good collateral status on functional outcome after $\operatorname{EVT}(44,48,49)$.

\section{Magnetic Resonance Imaging (MRI) and Magnetic Resonance Angiography (MRA)}

MRI/MRA can also be used to evaluate AIS and LVO. Diffusion weighted image (DWI) is highly sensitive and specific for the detection of early ischemic changes within the first $6 \mathrm{~h}$ of symptom onset (50-52). Early reversible ischemia has very mild depression in apparent diffusion coefficient (ADC) due to mild reduction in cerebral blood flow (CBF) $(50,51)$. Timely reperfusion therapy may reverse diffusion abnormalities (52). In the absence of reperfusion, diffusion abnormalities are often irreversible $(52,53)$. A good stroke MR protocol should include DWI, FLAIR, and SWI $(33,54)$. 
MRA is a good option for assessment of LVO and collateral circulation $(33,55)$. Time-of-flight (TOF) and contrast-enhanced (CE) MRA provide good vascular images through the neck and the Circle of Willis (55). CE MRA is performed with a rapid, short repetition time gradient echo sequence following an IV bolus of gadolinium. It is minimally invasive and offers better diagnostic accuracy than TOF-MRA in localizing LVO (55).

MRI/MRA were used as imaging tools in a few landmark studies $(16,17,19-22)$.

In SWIFT PRIME and REVASCAT, $17.4 \%$ and $5.3 \%$ of patients had MRI studies for patient screening $(15,16)$. The DAWN and DEFUSE 3 trials used more advanced imaging tools, including diffusion/perfusion MRI, for patient selection $(21,22)$.

Of note, the use of MRI/MRA for patient selection has some drawbacks. It takes time to screen the patients for metallic implants and to access the scanner $(33,54,55)$. The images tend to be more susceptible to patient motion. In addition, it is more difficult to monitor unstable patients in the MRI suite $(33,54)$.

\section{CT Perfusion (CTP) and Diffusion/Perfusion MRI}

Acute LVO may lead to significant reduction of cerebral blood flow $(\mathrm{CBF})$, resulting in a small irreversible infarct core and surrounding area of ischemic tissue that may be salvaged with prompt reperfusion (ischemic penumbra) $(56,57)$. Without reperfusion, the infarct core can expand and reach the size of the ischemic penumbra depending on duration of LVO and collaterals $(56,57)$.

CTP is a dynamic contrast-enhanced study developed for the analysis of the infarct core and ischemic penumbra per CBF, mean transition time (MTT) and cerebral blood volume (CBV) (58-62). The infarct core is defined as an area of brain tissue with more than $70 \%$ reduction in $\mathrm{CBF}$ compared to normal contralateral hemisphere and the ischemic penumbra is defined as an area with $>6 \mathrm{~s}$ of delayed arrival of contrast $(39,59-62)$. The ischemic penumbra is identified by a mismatch between CBF and $\mathrm{CBV}$, whereas the infarct core has a matched decrease in both CBF and CBV (61-64). The mismatch between infarct core and penumbra is an indirect measurement of collateral blood flow (49).

The diffusion/perfusion MRI is very sensitive in the detection of infarct core and perfusion mismatch (51, 61, 65-70). MRI may predict clinical response to early reperfusion therapy (6570). However, tissue at risk can be overestimated by perfusionweighted imaging (71).

Both CTP and MR perfusion images can be obtained with high-speed CT and MR imaging systems within $10 \mathrm{~min}$ (22, 61). The data processing is similar. CTP or diffusion/perfusion MRI was used to assess infarct core and ischemic penumbra in EXTEND-IA, SWIFT PRIME, EXTEND IA-TNK, DAWN, and DEFUSE 3 (14, 16, 21-23).

CTP was performed in $66.8 \%$ of the patients in the MR CLEAN trial (13). It was shown that a large infarct core was associated with poor functional outcome. Both EXTEND-IA and SWIFT-PRIME used CTP to select patients with small infarct core (IQR 4-32 and 0-16 ml, respectively) for EVT (Table 1)
$(14,16)$. Such strict selection criteria led to the highest rate of favorable outcome ever reported with EVT (60 and 71\%, respectively) $(14,16)$. However, these studies may have excluded patients who could benefit from $\operatorname{EVT}(16,64,72,73)$.

The DAWN trial evaluated the safety and efficacy of EVT for patients with LVO within 6-24h of last known well (21). Approximate $60 \%$ of the patients had wake-up stroke. The key inclusion criteria were severe clinical deficit and a small infarct core on MRI or CTP. The rate of functional independence at 90 days was $49 \%$ after EVT as compared to $13 \%$ in the control group.

In DEFUSE 3 trial, CTP was performed in $73 \%$ of the patients and diffusion/perfusion MRI was done in the other 27\% (22). Inclusion criteria includes an initial infarct volume $<70 \mathrm{ml}$, a ratio of ischemic penumbra to infarct core $\geq 1.8$, and an absolute mismatch $\geq 15 \mathrm{ml}$. The study enrolled patients with perfusion mismatch for EVT within 6-16 h after last known well. The rate of functional independence at 90 days was significantly higher than control group (45 vs. 17\%) (22).

Both DAWN and DEFUSE 3 trials demonstrated significant benefit of EVT within 16-24h of last known well by selecting patients with clinical-imaging mismatch (i.e., severe deficit and small infarct core) per advanced imaging tools. The median NIHSS score with IQR was $17(13-21)$ and 16 (10-20) while the median infarct core with IQR was $7.6(2-18)$ and $9.4(2.3-$ 25.6) $\mathrm{ml}$, respectively (Table 2$)(21,22)$. These results led to a paradigm shift from "time window" to "tissue window" per advanced perfusion imaging.

TABLE 2 | Clinical-infarct volume mismatch as eligibility criteria for EVT in recent landmark studies.

\begin{tabular}{|c|c|c|c|c|c|}
\hline & $\begin{array}{c}\text { Median } \\
\text { NIHSS (IQR) }\end{array}$ & $\begin{array}{c}\text { Median } \\
\text { ASPECTS } \\
\text { (IQR) }\end{array}$ & $\begin{array}{l}\text { Median infarct } \\
\text { core per } \\
\text { advanced } \\
\text { imaging-ml } \\
\text { (IQR) }^{\mathbf{a}}\end{array}$ & $\begin{array}{c}\text { sICH }^{b} \\
(\%)\end{array}$ & $\begin{array}{c}\text { Favorable } \\
\text { outcome } \\
(\%)\end{array}$ \\
\hline $\begin{array}{l}\text { MR CLEAN } \\
\text { (13) }\end{array}$ & $17(14-21)$ & $9(7-10)$ & - & 7.7 & 33 \\
\hline $\begin{array}{l}\text { EXTEND-IA } \\
(14)\end{array}$ & 17 (13-20) & $N R$ & $12(4-32)$ & 0 & 71 \\
\hline ESCAPE (15) & $16(13-20)$ & $9(8-10)$ & - & 3.6 & 53 \\
\hline $\begin{array}{l}\text { SWIFT PRIME } \\
\text { (16) }\end{array}$ & $17(13-20)$ & $9(8-10)$ & $6(0-16)$ & 1.0 & 60 \\
\hline $\begin{array}{l}\text { REVASCAT } \\
(17)\end{array}$ & $17(14-20)$ & 7 (6-9) & - & 1.9 & 44 \\
\hline $\begin{array}{l}\text { THERAPY } \\
\text { (18) }\end{array}$ & $17(14-21)$ & $7.5(6-9)$ & - & 9.3 & 38 \\
\hline THRACE (19) & 18 (15-21) & $5-10$ & - & 2 & 53 \\
\hline PISTE (20) & $18(6-24)$ & $5-10$ & - & 0 & 51 \\
\hline DAWN (21) & $17(13-21)$ & NR & $7.6(2.0-18.0)$ & 6 & 49 \\
\hline $\begin{array}{l}\text { DEFUSE } \\
3(22)\end{array}$ & $16(10-20)$ & $8(7-9)$ & $9.4(2.3-25.6)$ & 7 & 45 \\
\hline
\end{tabular}

$I Q R$, interquartile range; $N R$, not reported.

${ }^{a}$ Advanced imaging of perfusion CT or diffusion/perfusion MRI was used to quantify infarct core and ischemic penumbra $(14,16,21,22)$.

${ }^{b} \mathrm{~S} \mathrm{CH}$ was defined as intraparenchymal hematoma, subarachnoid hemorrhage, or intraventricular hemorrhage associated with a worsening of the NIHSS score by $\geq 4$ points within $24 h$ (3). 


\section{Patient Selection per Perfusion Imaging and Beyond}

Recent studies suggested that the selection criteria per advanced perfusion imaging in Dawn and DEFUSE 3 trials may have excluded a significant proportion of patients who could benefit from EVT. In a single center study of 79 patients comparing admission infarct core per CTP and final infarct on followup CT, Boned et al. showed that CTP overestimated infarct core for more than $10 \mathrm{~mL}$ in $38 \%$ of the patients (72). Therefore, CTPbased patient selection may deny treatment to patients who might benefit from reperfusion therapy. In a matched case-controlled study of patients with LVO on CTA and baseline ischemic core $>50 \mathrm{~mL}$ on CTP, EVT was associated with significantly improved functional outcome at 90 days (73). In a study of prospectively collected data, $38 \%$ of the DAWN-ineligible patients and $41 \%$ of DEFUSE 3-ineligible patients achieved functional independency at 90 days after EVT (74). In another retrospective study, 30\% of DAWN and/or DEFUSE-3 ineligible patients achieved functional independence after off-label EVT (75). Two additional studies showed that EVT could benefit patients with large infarct core (DWI-ASPECTS $\leq 5$ or DWI lesion $>70 \mathrm{~mL})(76,77)$. EVT was also reported to be safe and effective for patients who met all DAWN trial criteria but were treated beyond $24 \mathrm{~h}$ of last known well (78).

Figure 2 showed a typical example of EVT for wakeup stroke from middle cerebral artery occlusion. CTP or diffusion/perfusion MRI may be unnecessary in clinical practice in appropriately selected patients $(13,15-20)$.

\section{Major Complication of EVT: Symptomatic Intracranial Hemorrhage (sICH)}

The periprocedural sICH is the most feared complication of EVT $(13-22,57)$. Early pathophysiological responses to sudden LVO are distal vasodilation to compensate for dramatic reduction in tissue perfusion and subsequent loss of vascular reactivity. Reperfusion leads to blood overflow into the dilated vasculature, resulting in hyperperfusion, cerebral edema, capillary leak, or hemorrhage $(57,79)$. Endothelial cell injury and impairment of the blood-brain barrier (BBB) are likely the underlying mechanism of ICH (79). The primary predictors of sICH are infarct volume (80), low CBV (70), and severely delayed CBF due to poor collaterals (81). Intensive management of high blood pressure may reduce the risk of reperfusion injury and sICH (82).

The rate of sICH from EVT ranged from 0 to $9.3 \%$ in the 10 RCTs (Table 2). That was comparable to the risk of sICH in the medical arms (13-22). Meta-analysis of data from the 5 landmark studies published in 2015 showed that the rate of sICH increased only slightly with delayed EVT (35). EVT within 16-24 h of last known well was not associated with significant higher rate of $\operatorname{sICH}(21,22)$.

\section{Perspectives: From Time Window to Perfusion Mismatch and Beyond}

Advanced perfusion imaging used in the 4 landmark studies has helped demonstrating the best treatment effect of $\operatorname{EVT}(14,16)$. and extending the treatment window up to $16-24 \mathrm{~h}$ of last known well $(21,22)$. However, the median infarct core was only 12 ,
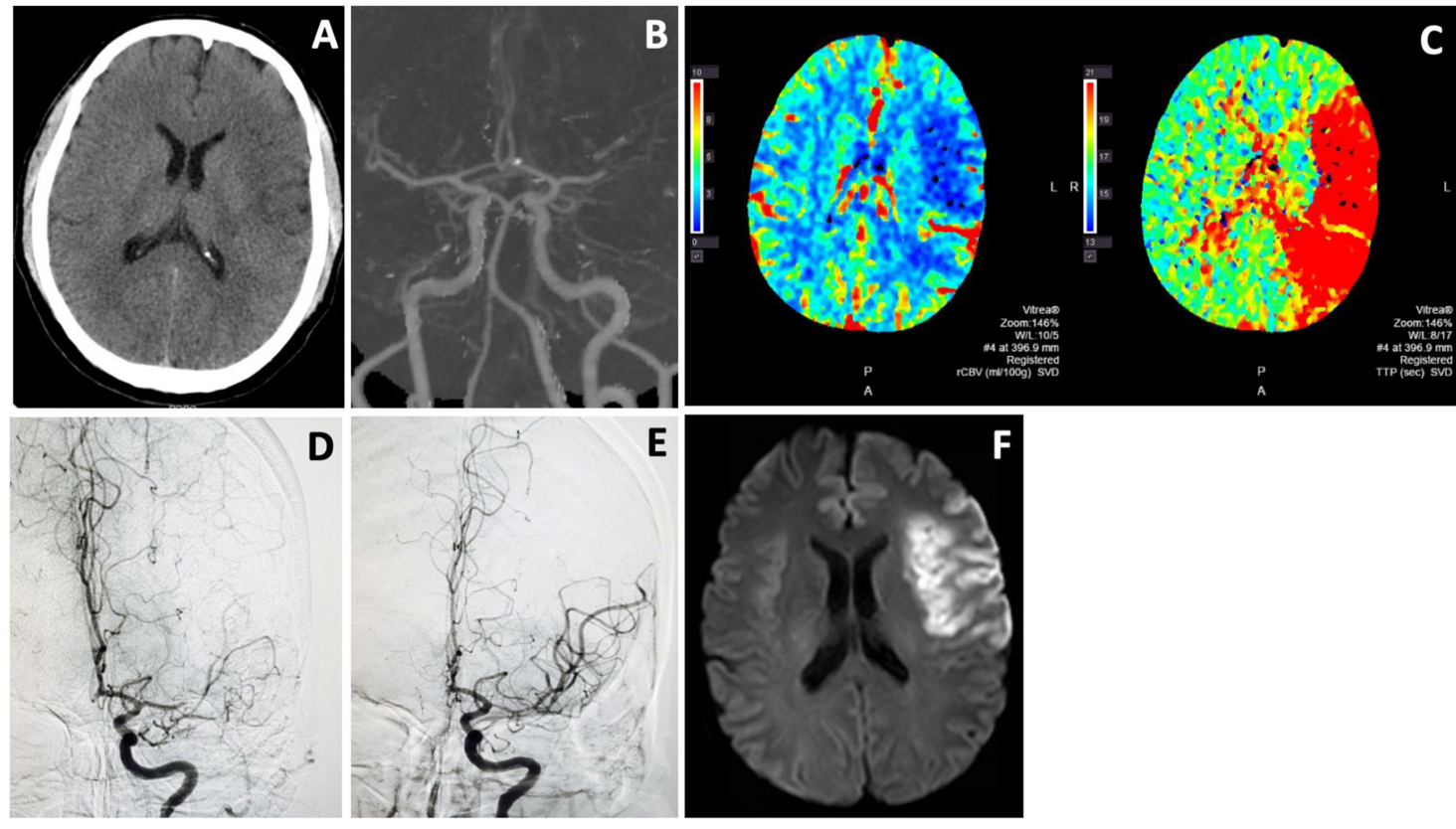

FIGURE 2 | Endovascular thrombectomy for wake-up stroke. A 44 years old man woke up with right sided weakness and global aphasia. Last known well was 8 p.m. the night before. NIHSS score was 15. Non-contrast CT showed subtle left frontal hypodensity with ASPECTS of 8 (A). CTA showed L MCA M1 occlusion (B) and CTP revealed a large ischemic penumbra (C). He underwent thrombectomy with excellent MCA recanalization (D,E). Follow-up MRI (F) showed an infarct in the left frontal region that was similar in size to the hypodense area on non-contrast CT and infarct core on CTP. He recovered well with only mild expressive aphasia at 3 month. 
6, 7.6, and $9.4 \mathrm{ml}$ in EXTEND-IA, SWIFT PRIME, DAWN, and DEFUSE 3 trials, respectively, (Table 2) $(14,16,21,22)$, as compared to $49.7 \mathrm{ml}$ in MR CLEAN $(13,83)$. Therefore, the best treatment effect in the studies using advance perfusion imaging is likely the results of strict selection of patients with small infarct core for $\operatorname{EVT}(14,16,21,22)$. There are increasing evidence to suggest the limitations of advanced imaging modalities in the real-world practice.

First, in a recent systematic review and meta-analysis of individual patient data from all recent RCTs that compared EVT with standard medical therapy, perfusion mismatch was not associated with either functional independence or functional improvement (84). Patient should not be excluded from EVT within $6 \mathrm{~h}$ of stroke onset purely on the basis of a large estimated ischemic core.

Second, the use of perfusion imaging for patient selection may cause delay in reperfusion therapy $(22,55)$. In a metaanalysis of pooled data from the 5 RCTs published in 2015, earlier treatment with EVT was associated with lower degrees of disability (84). The more recent meta-analysis showed that 30min delay in imaging-to-reperfusion time had a similar adverse effect on functional outcome as a $10-\mathrm{ml}$ increase in ischemic core volume (85). In a recent cohort study, the use of advanced modality imaging was shown to delay EVT without improvement in clinical outcomes (86).

Third, the selection criteria per advanced perfusion imaging may exclude a significant proportion of eligible patients (16, 73-77). CTP and MRI diffusion/perfusion were shown to overestimate infarct core $(71,72)$. A number of recent studies demonstrated that thrombectomy may benefit DAWN and/or DEFUSE-3 ineligible patients (73-77).

Last, perfusion imaging capability is not readily available, in particular, in developing regions. A significant proportion of eligible patients world-wide would be deprived from the proven therapy if perfusion imaging criteria be strictly adhered to in clinical practice.

When designing clinical trials, it makes sense to use advanced imaging tools for patient selection in order to achieve the best treatment effect in small sample size studies. Since EVT has been independently proven effective by 10 RCTs (13-22), it is imperative to provide the therapy to all eligible patients in the fastest puncture-to-reperfusion time.

Of the 10 RCTs that independently demonstrated the powerful efficacy of EVT, 8 validated the use of ASPECTS score for the assessment of early infarct $(13,15,17-20,22)$. As shown in Table 2, clinical-imaging mismatch (i.e., high NIHSS and ASPECTS) is clearly a good indication for EVT in the realworld practice.

\section{Proposed Simple Imaging Guide for EVT}

The ideal imaging guide for decision-making for EVT should be widely available, quick to perform and interpret, and sensitive for the detection of early infarct, LVO and collaterals (13-22, 39).

NIHSS is a good surrogate marker for clinical deficit $(87,88)$ and ASPECTS has been validated for the assessment of early infarct in the anterior circulation $(13,15,17-20,22,35)$. As shown in Table 1, all of the 10 recent RCTs used NIHSS scores as

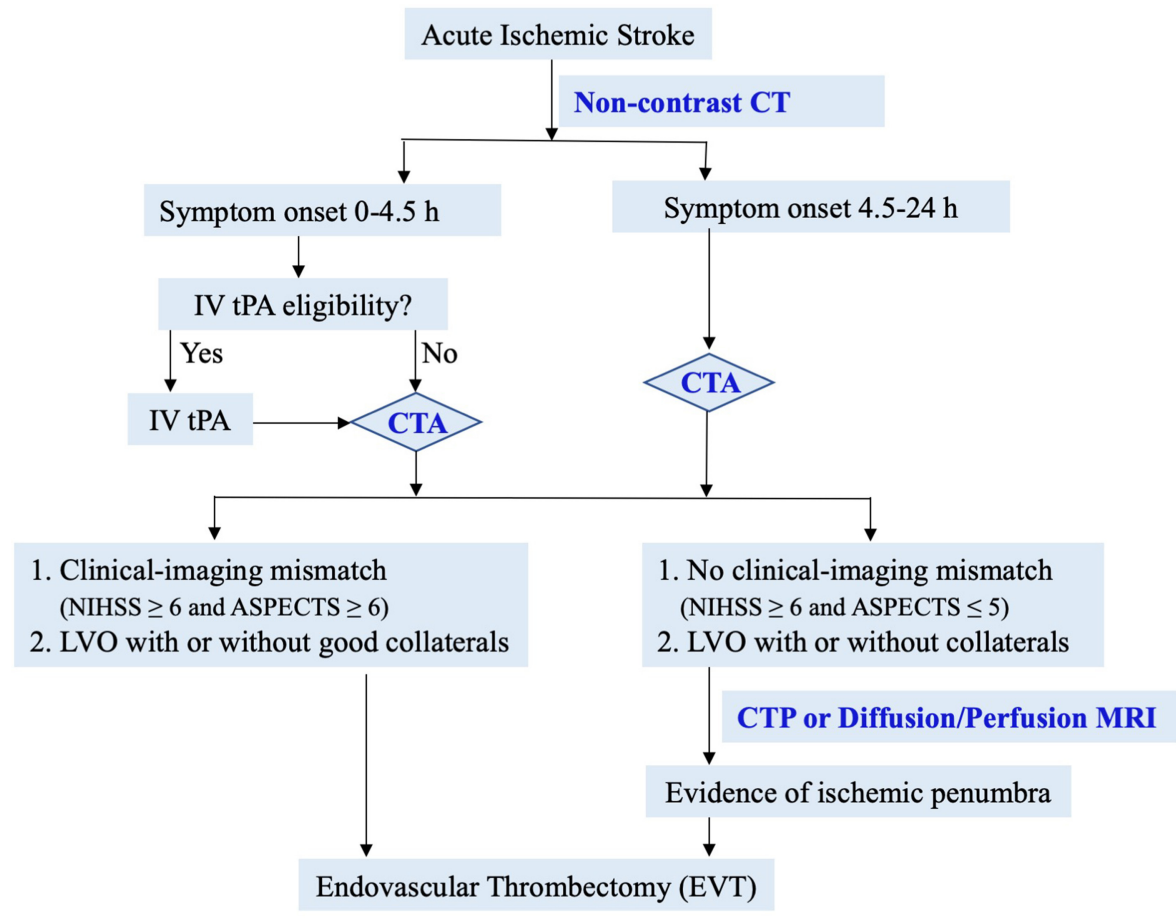

FIGURE 3 | Proposed simple imaging guide for endovascular thrombectomy. 
eligibility criteria $(\geq 2, \geq 5, \geq 6, \geq 8, \geq 10,8-29$, and 10-25) (1322). From these studies, there are insufficient data to determine whether there is an overall net benefit from EVT in patients with NIHSS score $2-5(13,15,89)$. A NIHSS score $\geq 6$ was the minimum used in 4 trials $(14,17,20,22)$, fulfilling the AHA's Level of A evidence. The other 4 trials used higher NIHSS score $(\geq 8)(16,18,19,21)$. Meta-analysis of the pooled data from the 5 RCTs published in 2015 showed strong efficacy of thrombectomy in patients with ASPECTS $\geq 6$ (35). Therefore, NIHSS $\geq 6$ and ASPECTS $\geq 6$ from LVO are evidence-based cut-off values for timely decision-making for thrombectomy $(90,91)$.

Based on data from recent landmark studies, we propose the following simple and efficient imaging guide for decision-making for EVT (Figure 3). In patients with suspected acute ischemic stroke, non-contrast CT is performed to assess IV tPA eligibility and ASPECTS score. CTA is then performed to evaluate LVO and collaterals. In patients with significant clinical-imaging mismatch (NIHSS $\geq 6$ and ASPECTS $\geq 6$ ) from LVO, EVT should be considered immediately per AHA guidelines $(90,91)$. In patients without clinical-imaging mismatch (NIHSS $\geq 6$ and ASPECTS $\leq 5$ ), advanced perfusion imaging is recommended to identify salvageable ischemic penumbra. This simple and efficient imaging protocol may lead to EVT for most eligible patients in the fastest onset-to-reperfusion time. Two recent studies have shown the safety and effectiveness of simplified imaging protocol in patients with wake-up or late presenting stroke $(89,92)$.

\section{REFERENCES}

1. The National Institute of Neurological Disorders and Stroke rt-PA Stroke Study Group. Tissue plasminogen activator for acute hemisphere stroke. N Engl J Med. (1995) 333:1581-7. doi: 10.1056/NEJM199512143332401

2. Hacke W, Kaste M, Bluhmki E, Brozman M, Dávalos A, Guidetti D, et al. Thrombolysis with alteplase 3 to 4.5 hours after acute ischemic stroke. $N$ Engl J Med. (2008) 359:1317-29. doi: 10.1056/NEJMoa0804656

3. Lees KR, Bluhmki E, von Kummer R, Brott TG, Toni D, Grotta JC, et al. Time to treatment with intravenous alteplase and outcome in stroke: an updated pooled analysis of ECASS, ATLANTIS, NINDS, and EPITHET trials. Lancet. (2010) 375:1695-703. doi: 10.1016/S0140-6736(10)60491-6

4. Bhatia R, Hill MD, Shobha N, Menon B, Bal S, Kochar P, et al. Low rates of acute recanalization with intravenous recombinant tissue plasminogen activator in ischemic stroke: real-world experience and a call for action. Stroke. (2010) 41:2254-8. doi: 10.1161/STROKEAHA.110.592535

5. Riedel CH, Zimmermann P, Jensen-Kondering U, Stingele R, Deuschl G, Jansen O.Riedel $\mathrm{CH}$, et al. The importance of size: successful recanalization by intravenous thrombolysis in acute anterior stroke depends on thrombus length. Stroke. (2011) 42:1775-7. doi: 10.1161/STROKEAHA.110.609693

6. Chopko BW, Kerber C, Wong W, Georgy B. Transcatheter snare removal of acute middle cerebral artery thromboembolism: technical case report. Neurosurgery. (2000) 46:1529-31. doi: 10.1097/00006123-200006000-00046

7. Mayer TE, Hamann GF, Brueckmann HJ. Treatment of basilar artery embolism with mechanical extraction device: necessity of flow reversal. Stroke. (2002) 33:2232-5. doi: 10.1161/01.STR.0000024524.71680.C6

8. Yu W, Binder D, Foster-Barber A, Malek R, Smith WS, Higashida RT. Endovascular embolectomy of acute basilar artery occlusion. Neurology. (2003) 61:1421-3. doi: 10.1212/WNL.61.10.1421

9. Broderick JP, Palesch YY, Demchuk AM, Yeatts SD, Khatri P, Hill $\mathrm{MD}$, et al. Endovascular therapy after intravenous tPA versus tPA alone for stroke. N Engl J Med. (2013) 368:893-903. doi: 10.1056/NEJMoa12 14300
Of note, ASPECTS has low inter-rater reliability, especially in early time window $(32,33,93)$. For patients with a high ASPECTS and a LVO on CTA, the ASPECTS-based guideline is an easy and fast protocol to safeguard earliest treatment. In cases with low ASPECTS ( $\leq 5)$ or uncertain eligibility, a multimodal imaging study should be used to rescue patients with salvageable ischemia.

\section{CONCLUSION}

EVT is a proven therapy for appropriately selected patients with AIS from LVO up to $24 \mathrm{~h}$ of symptom onset (13-22). Although advanced perfusion imaging may better define infarct core and ischemic penumbra, they have a number of limitations for the real-world practice. A simple imaging protocol with non-contrast CT and CTA to identify clinical-imaging mismatch (NIHSS $\geq$ 6 and ASPECTS $\geq 6$ ) from LVO may be the best guide for EVT in clinical practice. Advanced perfusion imaging is recommended in patients with large infarct core to identify additional candidates for the best possible care.

\section{AUTHOR CONTRIBUTIONS}

WY contributed to literature review, manuscript draft and final revision. W-JJ contributed to discussions of important intellectual contents and manuscript revision.
10. Kidwell CS, Jahan R, Gornbein J, Alger JR, Nenov V, Ajani Z, et al. A trial of imaging selection and endovascular treatment for ischemic stroke. $\mathrm{N} \mathrm{Engl} \mathrm{J}$ Med. (2013) 368:914-23. doi: 10.1056/NEJMoa1212793

11. Ciccone A, Valvassori L, Nichelatti M, Sgoifo A, Ponzio M, Sterzi R, et al. Endovascular treatment for acute ischemic stroke. N Engl J Med. (2013) 368:904-13. doi: 10.1056/NEJMoa1213701

12. Demchuk AM, Goyal M, Yeatts SD, Carrozzella J, Foster LD, Qazi E, et al. for the IMS III Investigators. Recanalization and clinical outcome of occlusion sites at baseline CT angiography in the Interventional Management of Stroke III trial. Radiology. (2014) 273:202-10. doi: 10.1148/radiol.14132649

13. Berkhemer OA, Fransen PS, Beumer D, van den Berg LA, Lingsma HF, Yoo AJ, et al. A randomized trial of intraarterial treatment for acute ischemic stroke. N Engl J Med. (2015) 372:11-20. doi: 10.1056/NEJMoa1411587

14. Campbell BC, Mitchell PJ, Kleinig TJ, Dewey HM, Churilov L, Yassi N, et al. Endovascular therapy for ischemic stroke with perfusion-imaging selection. $N$ Engl J Med. (2015) 372:1009-18. doi: 10.1056/NEJMoa1414792

15. Goyal M, Demchuk AM, Menon BK, Eesa M, Rempel JL, Thornton J, et al. Randomized assessment of rapid endovascular treatment of ischemic stroke. N Engl J Med. (2015) 372:1019-30. doi: 10.1056/NEJMoa1414905

16. Saver JL, Goyal M, Bonafe A, Diener HC, Levy EI, Pereira VM, et al. Stentretriever thrombectomy after intravenous t-PA vs. t-PA alone in stroke. $N$ Engl J Med. (2015) 372:2285-95. doi: 10.1056/NEJMoa1415061

17. Jovin TG, Chamorro A, Cobo E, de Miquel MA, Molina CA, Rovira A, et al. Thrombectomy within 8 hours after symptom onset in ischemic stroke. $N$ Engl J Med. (2015) 372:2296-06. doi: 10.1056/NEJMoa1503780

18. Mocco J, Zaidat OO, von Kummer R, Yoo AJ, Gupta R, Lopes D, et al. THERAPY Trial Investigators. Aspiration thrombectomy after intravenous alteplase versus intravenous alteplase alone. Stroke. (2016) 47:2331-8. doi: 10.1161/STROKEAHA.116.013372

19. Bracard S, Ducrocq X, Mas JL, Soudant M, Oppenheim C, Moulin T, et al. Mechanical thrombectomy after intravenous alteplase versus alteplase alone after stroke (THRACE): a randomised controlled trial. Lancet Neurol. (2016) 15:1138-47. doi: 10.1016/S1474-4422(16)30177-6 
20. Muir KW, Ford GA, Messow CM, Ford I, Murray A, Clifton A, et al. PISTE Investigators. Endovascular therapy for acute ischaemic stroke: the Pragmatic Ischaemic Stroke Thrombectomy Evaluation (PISTE) randomised, controlled trial. J Neurol Neurosurg Psychiatry. (2017) 88:38-44. doi: 10.1136/jnnp-2016-314117

21. Nogueira, RG, Jadhav, AP, Haussen, DC Thrombectomy 6 to 24 hours after stroke with a mismatch between deficit and infarct. N Engl J Med. (2018) 378:11-21. doi: 10.1056/NEJMoa1706442

22. Albers, GW, Marks, MP, Kemp, S. Thrombectomy for stroke at 6 to 16 hours with selection by perfusion imaging. N Engl J Med. (2018) 378:708-18. doi: 10.1056/NEJMoa1713973

23. Campbell BCV, Mitchell PJ, Churilov L, Yassi N, Kleinig TJ, Dowling RJ, et al. Tenecteplase versus alteplase before thrombectomy for ischemic stroke. $N$ Engl J Med. (2018) 378:1573-82. doi: 10.1056/NEJMoa1716405

24. von Kummer R, Allen KL, Holle R, Bozzao L, Bastianello S, Manelfe C, et al. Acute stroke: usefulness of early CT findings before thrombolytic therapy. Radiology. (1997) 205:327-33. doi: 10.1148/radiology.205.2.9356611

25. Dippel DW, Du Ry van Beest Holle M, van Kooten F, Koudstaal PJ. The validity and reliability of signs of early infarction on CT in acute ischaemic stroke. Neuroradiology. (2000) 42:629-33. doi: 10.1007/s002340000369

26. Barber PA, Demchuk AM, Zhang J, Buchan AM, for the ASPECTS Study Group. The validity and reliability of a novel quantitative CT score in predicting outcome in hyperacute stroke prior to thrombolytic therapy. Lancet. (2000) 355:1670-4. doi: 10.1016/S0140-6736(00)02237-6

27. Hill MD, Demchuk AM, Goyal M, Jovin TG, Foster LD, Tomsick TA, et al. Alberta stroke program early computed tomography score to select patients for endovascular treatment interventional management of stroke (IMS)-III trial. Stroke. (2014) 45:444-9. doi: 10.1161/STROKEAHA.113.003580

28. Coutts SB, Lev MH, Eliasziw M, Roccatagliata L, Hill MD, Schwamm LH, et al. ASPECTS on CTA source images versus unenhanced CT: added value in predicting final infarct extent and clinical outcome. Stroke. (2004) 35:2472-6. doi: 10.1161/01.STR.0000145330.14928.2a

29. Barber PA, Hill MD, Eliasziw M, Demchuk AM, Pexman JH, Hudon ME, et al. ASPECTS Study Group. Imaging of the brain in acute ischaemic stroke: comparison of computed tomography and magnetic resonance diffusion-weighted imaging. J Neurol Neurosurg Psychiatry. (2005) 76:152833. doi: 10.1136/jnnp.2004.059261

30. Phan TG, Donnan GA, Koga M, Mitchell LA, Molan M, Fitt G, et al. The ASPECTS template is weighted in favor of the striatocapsular region. Neuroimage. (2006) 31:477-81. doi: 10.1016/j.neuroimage.2005.12.059

31. Schröder J, Thomalla G.Schröder J, Thomalla G. A critical review of Alberta Stroke Program Early CT Score for evaluation of acute stroke imaging. Front Neurol. (2017) 7:245. doi: 10.3389/fneur.2016.00245

32. Schröder J, Cheng B, Ebinger M, Köhrmann M, Wu O, Kang DW, et al. Validity of acute stroke lesion volume estimation by diffusionweighted imaging-Alberta stroke program early computed tomographic score depends on lesion location in 496 patients with middle cerebral artery stroke. Stroke. (2014) 45:3583-8. doi: 10.1161/STROKEAHA.114.006694

33. Chalela JA, Kidwell CS, Nentwich LM, Luby M, Butman JA, Demchuk AM, et al. Magnetic resonance imaging and computed tomography in emergency assessment of patients with suspected acute stroke: a prospective comparison. Lancet. (2007) 369:293-8. doi: 10.1016/S0140-6736(07)60151-2

34. Coutts SB, Hill MD, Demchuk AM, Barber PA, Pexman JH, Buchan AM. ASPECTS reading requires training and experience. Stroke. (2003) 34:e179. doi: 10.1161/01.STR.0000092221.81498.91

35. Goyal M, Menon BK, van Zwam WH, Dippel DW, Mitchell PJ, Demchuk AM, et al. Endovascular thrombectomy after large-vessel ischaemic stroke: a metaanalysis of individual patient data from five randomised trials. Lancet. (2016) 387:1723-31. doi: 10.1016/S0140-6736(16)00163-X

36. Lev MH, Farkas J, Rodriguez VR, Schwamm LH, Hunter GJ, Putman $\mathrm{CM}$, et al. CT angiography in the rapid triage of patients with hyperacute stroke to intraarterial thrombolysis: accuracy in the detection of large vessel thrombus. J Comput Assist Tomogr. (2001) 25:520-28. doi: 10.1097/00004728-200107000-00003

37. Maas MB, Lev MH, Ay H, Singhal AB, Greer DM, Smith WS, et al. Collateral vessels on CT angiography predict outcome in acute ischemic stroke. Stroke. (2009) 40:3001-5. doi: 10.1161/STROKEAHA.109.552513

38. Menon BK, d'Esterre CD, Qazi EM, Almekhlafi M, Hahn L, Demchuk $\mathrm{AM}$, et al. Multiphase CT angiography: a new tool for the imaging triage of patients with acute ischemic stroke. Radiology. (2015) 275:510-20. doi: 10.1148 /radiol.15142256

39. Menon BK, Campbell BC, Levi C, Goyal M. Role of imaging in current acute ischemic stroke workflow for endovascular therapy. Stroke. (2015) 46:1453-61. doi: 10.1161/STROKEAHA.115.009160

40. Bhatia R, Bal SS, Shobha N, Menon BK, Tymchuk S, Puetz V, et al. $\mathrm{CT}$ angiographic source images predict outcome and final infarct volume better than non-contrast CT in proximal vascular occlusions. Stroke. (2011) 42:1575-80. doi: 10.1161/STROKEAHA.110.603936

41. Pulli B, Schaefer PW, Hakimelahi R, Chaudhry ZA, Lev MH, Hirsch JA, et al. Acute ischemic stroke: infarct core estimation on CT angiography source images depends on CT angiography protocol. Radiology. (2012) 262:593-604. doi: 10.1148/radiol.11110896

42. Liebeskind DS, Tomsick TA, Foster LD, Yeatts SD, Carrozzella J, Demchuk AM, et al. Collaterals at angiography and outcomes in the interventional management of stroke (ims) iii trial. Stroke. (2014) 45:759-64. doi: 10.1161/STROKEAHA.113.004072

43. Miteff F, Levi CR, Bateman GA, Spratt N, McElduff P, Parsons MW. The independent predictive utility of computed tomography angiographic collateral status in acute ischaemic stroke. Brain. (2009) 132:2231-8. doi: 10.1093/brain/awp155

44. Leng X, Fang H, Leung TW, Mao C, Miao Z, Liu L, et al. Impact of collaterals on the efficacy and safety of endovascular treatment in acute ischemic stroke: a systematic review and meta-analysis. J Neurol Neurosurg Psychiatry. (2015) 87:1-8. doi: 10.1136/jnnp-2015-310965

45. Ribo M, Flores A, Rubiera M, Pagola J, Sargento-Freitas J, RodriguezLuna D, et al. Extending the time window for endovascular procedures according to collateral pial circulation. Stroke. (2011) 42:3465-9. doi: 10.1161/STROKEAHA.111.623827

46. Bang OY, Saver JL, Kim SJ, Kim GM, Chung CS, Ovbiagele B, et al. Collateral flow predicts response to endovascular therapy for acute ischemic stroke. Stroke. (2011) 42:693-9. doi: 10.1161/STROKEAHA.110.595256

47. Bang OY, Saver JL, Kim SJ, Kim GM, Chung CS, Ovbiagele B, et al. Collateral flow averts hemorrhagic transformation after endovascular therapy for acute ischemic stroke. Stroke. (2011) 42:2235-9. doi: 10.1161/STROKEAHA.110.604603

48. Hwang YH, Kang DH, Kim YW, Kim YS, Park SP, Liebeskind DS. Impact of time-to-reperfusion on outcome in patients with poor collaterals. AJNR Am J Neuroradiol. (2015) 36:495-500. doi: 10.3174/ajnr.A4151

49. Bang OY, Goyal M, Liebeskind DS.Bang OY, Goyal M, Liebeskind DS. Collateral circulation in ischemic stroke: assessment tools and therapeutic strategies. Stroke. (2015) 46:3302-9. doi: 10.1161/STROKEAHA.115. 010508

50. Warach S, Gaa J, Siewert B, Wielopolski P, Edelman RR. Acute human stroke studied by whole brain echo planar diffusion-weighted magnetic resonance imaging. Ann Neurol. (1995) 37:231-41. doi: 10.1002/ana.410370214

51. Tong DC, Yenari MA, Albers GW. O’Brien M, Marks MP, Moseley ME. Correlation of perfusion- and diffusion-weighted MRI with NIHSS score in acute ( $<6.5$ hour) ischemic stroke. Neurology. (1998) 50:864-9. doi: 10.1212/WNL.50.4.864

52. Lövblad KO, Laubach HJ, Baird AE, Curtin F, Schlaug G, Edelman RR, et al. Clinical experience with diffusion-weighted $\mathrm{MR}$ in patients with acute stroke. AJNR Am J Neuroradiol. (1998) 19:1061-6.

53. Grant PE, He J, Halpern EF, Wu O, Schaefer PW, Schwamm LH, et al. Frequency and clinical context of decreased apparent diffusion coefficient reversal in the human brain. Radiology. (2001) 221:43-50. doi: 10.1148/radiol.2211001523

54. Muir KW, Buchan A, von Kummer R et al. Imaging of acute stroke. Lancet Neurol. (2006) 5:755-68. doi: 10.1016/S1474-4422(06)70545-2

55. Vu D, Gonzalez RG, Schaefer P. Conventional MRI and MR angiography of stroke. In: Gonzalez RG, Hirsch J, Koroshetz W, et al, editors. Acute Ischemic Stroke: Imaging and Intervention. Berlin: Springer-Verlag (2006). p. 115-35.

56. Astrup J, Siesjö BK, Symon L. Thresholds in cerebral ischemiathe ischemic penumbra. Stroke. (1981) 12:723-5. doi: 10.1161/01.STR. 12.6.723

57. Yu W., Liu L. Therapeutic Window Beyond Cerebral Ischemic Reperfusion Injury. In: Jiang W, Yu W, Qu Y, Shi Z, Luo B., Zhang J. editors. Cerebral Ischemic Reperfusion Injuries (CIRI). Springer Series in Translational Stroke Research. Cham: Springer Nature (2018). p. 245-59. 
58. Koenig M, Klotz E, Luka B, Venderink DJ, Spittler JF, Heuser L. Perfusion CT of the brain: diagnostic approach for early detection of ischemic stroke. Radiology. (1998) 209:85-93. doi: 10.1148/radiology.209.1.9769817

59. Koenig M, Kraus M, Theek C, Klotz E, Gehlen W, Heuser L. Quantitative assessment of the ischemic brain by means of perfusionrelated parameters derived from perfusion CT. Stroke. (2001) 32:431-7. doi: 10.1161/01.STR.32.2.431

60. Wintermark M, Reichhart M, Thiran JP, Maeder P, Chalaron M, Schnyder P, et al. Prognostic accuracy of cerebral blood flow measurement by perfusion computed tomography, at the time of emergency room admission, in acute stroke patients. Ann Neurol. (2002) 51:417-32. doi: 10.1002/ana. 10136

61. Schramm P, Schellinger PD, Klotz E, Kallenberg K, Fiebach JB, Külkens $\mathrm{S}$, et al. Comparison of perfusion computed tomography and computed tomography angiography source images with perfusion-weighted imaging and diffusion-weighted imaging in patients with acute stroke of less than 6 hours' duration. Stroke. (2004) 35:1652-58. doi: 10.1161/01.STR.0000131271. 54098.22

62. Murphy BD, Fox AJ, Lee DH, Sahlas DJ, Black SE, Hogan MJ, et al. Identification of penumbra and infarct in acute ischemic stroke using computed tomography perfusion-derived blood flow and blood volume. Stroke. (2006) 37:1771-7. doi: 10.1161/01.STR.0000227243.96808.53

63. Turk A, Magarik JA, Chaudry I, Turner RD, Nicholas J, Holmstedt CA, et al. CT perfusion-guided patient selection for endovascular treatment of acute ischemic stroke is safe and effective. J Neurointerv Surg. (2012) 4:261-5. doi: 10.1136/neurintsurg-2011-010067

64. Bouslama M, Haussen DC, Grossberg JA, Dehkharghani S, Bowen MT, Rebello LC, et al. Computed tomographic perfusion selection and clinical outcomes after endovascular therapy in large vessel occlusion stroke. Stroke. (2017) 48:1271-7. doi: 10.1161/STROKEAHA.116.015636

65. Barber PA, Darby DG, Desmond PM, Yang Q, Gerraty RP, Jolley D, et al. Prediction of stroke outcome with echoplanar perfusion- and diffusionweighted MRI. Neurology. (1998) 51:418-26. doi: 10.1212/WNL.51.2.418

66. Rordorf G, Koroshetz WJ, Copen WA, Cramer SC, Schaefer PW, Budzik RF, et al. Regional ischemia and ischemic injury in patients with acute middle cerebral artery stroke as defined by early diffusion-weighted and perfusionweighted MRI. Stroke. (1998) 29:939-43. doi: 10.1161/01.STR.29.5.939

67. Kidwell CS, Saver JL, Mattiello J, Starkman S, Vinuela F, Duckwiler G, et al. Thrombolytic reversal of acute human cerebral ischemic injury shown by diffusion/perfusion magnetic resonance imaging. Ann Neurol. (2000) 47:462-9. doi: 10.1002/1531-8249(200004)47:4<462::AID-ANA9>3.0.CO;2-Y

68. Thijs VN, Adami A, Neumann-Haefelin T, Moseley ME, Marks MP, Albers GW. Relationship between severity of MR perfusion deficit and DWI lesion evolution. Neurology. (2001) 57:1205-11. doi: 10.1212/WNL.57.7.1205

69. Røhl L, Ostergaard L, Simonsen CZ, Vestergaard-Poulsen P, Andersen G, Sakoh M, et al. Viability thresholds of ischemic penumbra of hyperacute stroke defined by perfusion-weighted MRI and apparent diffusion coefficient. Stroke. (2001) 32:1140-6. doi: 10.1161/01.STR.32.5.1140

70. Albers GW, Thijs VN, Wechsler L, Kemp S, Schlaug G, Skalabrin E et al. Magnetic resonance imaging profiles predict clinical response to early reperfusion: the diffusion and perfusion imaging evaluation for understanding stroke evolution (DEFUSE) study. Ann Neurol. (2006) 60:50817. doi: 10.1002/ana.20976

71. Kucinski T, Naumann D, Knab R, Schoder V, Wegener S, Fiehler J, et al. Tissue at risk is overestimated in perfusion-weighted imaging: MR imaging in acute stroke patients without vessel recanalization. AJNR Am J Neuroradiol. (2005) 26:815-9.

72. Boned S, Padroni M, Rubiera M, Tomasello A, Coscojuela P, Romero $\mathrm{N}$, et al. Admission CT perfusion may overestimate initial infarct core: the ghost infarct core concept. J Neurointerv Surg. (2017) 9:66-9. doi: 10.1136/neurintsurg-2016-012494

73. Rebello LC, Bouslama M, Haussen DC, Dehkharghani S, Grossberg JA, Belagaje S, et al. Endovascular treatment for patients with acute stroke who have a large ischemic core and large mismatch imaging profile. JAMA Neurol. (2017) 74:34-40. doi: 10.1001/jamaneurol.2016.3954

74. Ducroux C, Khoury N, Lecler A, Blanc R, Chetrit A, Redjem H. Application of the DAWN clinical imaging mismatch and DEFUSE 3 selection criteria: benefit seems similar but restrictive volume cut-offs might omit potential responders. Eur J Neurol. (2018) 25:1093-9. doi: 10.1111/ene. 13660
75. Desai SM, Rocha M, Molyneaux BJ, Starr M, Kenmuir CL, Gross BA, et al. Thrombectomy 6-24 hours after stroke in trial ineligible patients. J NeuroInterventional Surg. (2018) 10:1-6. doi: 10.1136/neurintsurg-2018-013915

76. Gautheron V, Xie Y, Tisserand M, Raoult H, Soize S, Naggara O, et al. Outcome after reperfusion therapies in patients with large baseline diffusion-weighted imaging stroke lesions: A THRACE Trial (Mechanical Thrombectomy After Intravenous alteplase versus alteplase alone after stroke) subgroup analysis. Stroke. (2018) 49:750-3. doi: 10.1161/STROKEAHA.117.020244

77. Manceau PF, Soize S, Gawlitza M, Fabre G, Bakchine S, Durot C. Is there a benefit of mechanical thrombectomy in patients with large stroke (DWIASPECTS $\leq$ 5)? Eur J Neurol. (2018) 25:105-10. doi: 10.1111/ene.13460

78. Desai SM, Haussen DC, Aghaebrahim A, Al-Bayati AR, Santos R, Nogueira RG, et al. Thrombectomy 24 hours after stroke: beyond DAWN. J NeuroInterventional Surg. (2018) 10:1039-42. doi: 10.1136/neurintsurg-2018-013923

79. Ramadan NM.Khatri P, McKinney AM, Swenson B, et al: Blood- brain barrier, reperfusion injury, and hemorrhagic transformation in acute ischemic stroke. Neurology. (2012) 79 (suppl. 1):S52-7. doi: 10.1212/WNL.0b013e3182697e70

80. Singer OC, Humpich MC, Fiehler J, Albers GW, Lansberg MG, Kastrup A, et al. Risk for symptomatic intracerebral hemorrhage after thrombolysis assessed by diffusion-weighted magnetic resonance imaging. Ann Neurol. (2008) 63:52-60. doi: 10.1002/ana.21222

81. Campbell BC, Christensen S, Parsons MW, Churilov L, Desmond PM, Barber PA et al. Advanced imaging improves prediction of hemorrhage after stroke thrombolysis. Ann Neurol. (2013) 73:510-9. doi: 10.1002/ana.23837

82. Abou-Chebl A, Reginelli J, Bajzer CT, Yadav JS. Intensive treatment of hypertension decreases the risk of hyperperfusion and intracerebral hemorrhage following carotid artery stenting. Catheter Cardiovasc Interv. (2007) 69:690-6. doi: 10.1002/ccd.20693

83. Geuskens RR, Borst J, Lucas M, Boers AM, Berkhemer OA, Roos YB, et al. MR CLEAN Trial Investigators. Characteristics of misclassified CT perfusion ischemic core in patients with acute ischemic stroke. PLoS ONE. (2015) 10:e0141571. doi: 10.1371/journal.pone.0141571

84. Saver JL, Goyal M, van der Lugt A, Menon BK, Majoie CB, Dippel $\mathrm{DW}$, et al. Time to treatment with endovascular thrombectomy and outcomes from ischemic stroke: a meta-analysis. JAMA. (2016) 316:1279-88. doi: 10.1001/jama.2016.12266

85. Campbell BCV, Majoie CBLM, Albers GW, Menon BK, Yassi N, Sharma $\mathrm{G}$ et al. for the HERMES collaborators. Penumbral imaging and functional outcome in patients with anterior circulation ischaemic stroke treated with endovascular thrombectomy versus medical therapy: a metaanalysis of individual patient-level data. Lancet Neurol. (2019) 18:46-55. doi: 10.1016/S1474-4422(18)30314-4

86. Sheth KN, Terry JB, Nogueira RG, Horev A, Nguyen TN, Fong AK, et al. Advanced modality imaging evaluation in acute ischemic stroke may lead to delayed endovascular reperfusion therapy without improvement in clinical outcomes. J Neurointerv Surg.(2013) 5(suppl 1): i62-i65. doi: 10.1136/neurintsurg-2012-010512

87. Adams HP, Davis PH, Leira EC, Chang KC, Bendixen BH, Clarke WR, et al. Baseline NIH Stroke Scale score strongly predicts outcome after stroke: a report of the Trial of Org 10172 in Acute Stroke Treatment (TOAST). Neurology. (1999) 53:126-31. doi: 10.1212/WNL.53.1.126

88. Frankel MR, Morgenstern LB, Kwiatkowski T, Lu M, Tilley BC, Broderick JP, et al. Predicting prognosis after stroke: a placebo group analysis from the National Institute of Neurological Disorders and Stroke rt-PA Stroke Trial. Neurology. (2000) 55:952-9. doi: 10.1212/WNL.55.7.952

89. Nagel S, Herweh C, Pfaff JAR, Schieber S, Schönenberger S, Möhlenbruch MA, et al. Simplified selection criteria for patients with longer or unknown time to treatment predict good outcome after mechanical thrombectomy. J NeuroInterventional Surg. (2018). doi: 10.1136/neurintsurg-2018-014347. [Epub ahead of print].

90. Powers WJ, Derdeyn CP, Biller J, Coffey CS, Hoh BL, Jauch EC, et al. 2015 AHA/ASA focused update of the 2013 guidelines for the early management of patients with acute ischemic stroke regarding endovascular treatment: a guideline for healthcare professionals from the American Heart Association/American Stroke Association. Stroke. (2015) 46:3020-35. doi: $10.1161 /$ STR.0000000000000074

91. Powers WJ, Rabinstein AA, Ackerson T, Adeoye OM, Bambakidis NC, Becker $\mathrm{K}$ et al. on behalf of the American Heart Association Stroke 
Council. 2018 Guidelines for the early management of patients with acute ischemic stroke: a guideline for healthcare professionals from the American Heart Association/American Stroke Association. Stroke. (2018) 49:e46-110. doi: 10.1161/STR.0000000000000172

92. Santos T, Carvalho A, Cunha AA, Rodrigues M, Gregório T, Paredes L et al. NCCT and CTA-based imaging protocol for endovascular treatment selection in late presenting or wake-up strokes. J NeuroInterventional Surg. (2019) 11:200-3. doi: 10.1136/neurintsurg-2018-014051

93. McTaggart RA, Jovin TG, Lansberg MG, Mlynash M, Jayaraman MV, Choudhri OA, et al. Alberta stroke program early computed tomographic scoring performance in a series of patients undergoing computed tomography and MRI: reader agreement, modality agreement, and outcome prediction. Stroke. (2015) 46:407-412. doi: 10.1161/STROKEAHA.114.006564
Conflict of Interest Statement: WY is a scientific consultant at Stryker Neurovascular.

The remaining author declares that the research was conducted in the absence of any commercial or financial relationships that could be construed as a potential conflict of interest.

Copyright (c) $2019 \mathrm{Yu}$ and Jiang. This is an open-access article distributed under the terms of the Creative Commons Attribution License (CC BY). The use, distribution or reproduction in other forums is permitted, provided the original author(s) and the copyright owner(s) are credited and that the original publication in this journal is cited, in accordance with accepted academic practice. No use, distribution or reproduction is permitted which does not comply with these terms. 